\title{
Mutual conditioning of gender and love: Towards a non-gendered idea of humanity
}

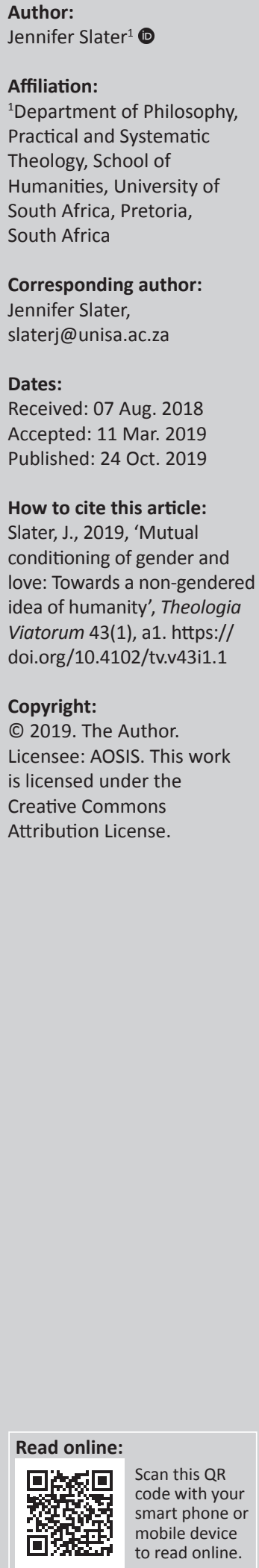

It is a presumed opinion that gender and love mutually condition each other and that this presumption ought to be embraced by cultural norms, religion, human rights and the ethic of freedom. The notion of mutual conditioning presupposes a healthy and principled environment that facilitates the free dynamic interaction between gender and love. It is the purpose of this article to explore the outcomes of the gender revolution and the additional strands of complexities that it contributed to the human condition. Although feminism has created terminologies such as sex and gender, it is believed that these words have outlived their usefulness to make way for the present-day evolution towards a non-gendered idea of humanity. Gender diversity seeks mutuality, and true love accommodates multiplicity; hence, the interacting and intra-acting of gender and love inevitably come face-to-face with cultural, legal, social, religious and moral milieus that hamper or even contradict the concept of mutual conditioning. This article seeks to trace the evolution of gender within diverse cultural constructions created by new liberal living conditions, but which have not yet infiltrated the diverse cultural domains where gender remains an entity without cultural freedom and therefore undermines the process of mutual conditioning of gender and love. The idea of gender as transcending bodily sex forms part of an old theological and philosophical debate; it, however, resurfaces here while revisiting Aristotle's idea of a non-gendered society or humanity. A degendered society implies a society that is free from dependence on gender, whereas a non-gendered humanity transcends gender divisions and associations, with its aspirations linked to the transcendence or consciousness of human nature. Love, in this sense, transcends all human dissections, and this article ascertains its capacity to mutually condition the diversity of gender and love.

Keywords: mutual conditioning; degendered; non-gendered; androgyne; animalism; transcendence; liminar.

\section{Introduction}

According to Jennifer Finney Boylan, 'The only debatable text for gender is the truth of a person's life, the lives we live each day' ('The XY Games', New York Times, 8/03/08). Anne Edwards (an Australian feminist) is of the opinion that although feminism has created the terminology of sex and gender, these distinctions have outlived their usefulness (Edwards 2010:1-12). The distinction was constructed on 'sex as the biological component, and gender as the cultural aspect of the differences between men and women' (Edwards 2010). Psychologists such as Robert Stoller (1968), in his work on Sex and Gender, rank the primacy of gender over sex in the formation of a person's individual identity. Feminists such as Denise Thompson (1989:147) would like to see feminism dispense with the word 'gender', simply because it has become embedded with feminist discourse and connected to the term sex. The evolution of the gender concept has brought complications to the notion of gender, as it is no longer as straightforward as it appears to be on the surface; it is in fact very intricate in the sense that it is a conglomeration of several factors. It is not easy to make sense of all the various arrangements of gender. The understanding of gender is not unilateral either as it is connected to various ingredients pertaining to biology, anatomy, hormones, psychology, culture and sociology. Various terms related to gender identity have proliferated: transgender, agender, genderqueer, genderfluid, gender identity, cisgender, gender binary or non-binary, gender expression, gender conforming or nonconforming (National Geographic 2017), together with a host of other terms that have added to the perplexity around each expression. Then there are also other terms that connect to sexual identity and clamour for clarification: male and female, man and woman, feminine and masculine, transsexual, intersex and androgynous (hermaphrodite). Each of these terms can be defined and positioned in the gamut of gender diversity or sexual diversity. What about the genderless, the asexual and the sexless? If there are so many variations related to the terms gender and sex, how does one 
talk about gender identity and how does one talk about mutual conditioning of gender and love. The question asked here is if there is so much diversity, where is the mutuality? This study explores the mutual conditioning of gender and love in a contentious environment of theological, cultural and human rights discourse. Gender is central to our self-understanding, and gender scholarship claims that gender is not a given, and requires more informed reflection. 'Sex is a biological categorisation based primarily on reproductive potential, whereas gender is the social elaboration of biological sex' (Eckert \& McConnell-Ginet 2003:2). Gendered performances are available to everyone, but society insists on matching up gender performance with biologically based sex assignments (Eckert \& McConnellGinet 2003:2). Gender builds on biological sex, but it exaggerates the biological difference and carries biological difference into irrelevant domains. However, nature and nurture intertwine, and there is no obvious point at which sex leaves off and gender begins.

\section{The sexual revolution}

The 1960s became known as the era of sexual revolution, whereas the 21st century is known as the age of gender revolution. The so-called sexual revolution is also known as a counter-cultural revolution as the conventional status quo was challenged by activism in the search for self and the autonomy of the self. Much of this time was marked by changes towards sexual attitudes and behaviour. Feminists, protagonists of gay rights and hippies were all advocates for this fight for change. This period was characterised by a dramatic shift from conventional values connected to sex and sexuality, social norms and actions. Clamouring for these changes was spearheaded by civil rights movements, women's organisations and especially young people who gave credence to birth control pills and related products. The use of the Pill, as it became known, enabled women to pursue professional careers and high qualifications. The first contraceptive pill was the result of the Women's Rights campaigner Margaret Sanger (1879-1966), who sponsored its development by raising money for its production and distribution (Baker 2012:7). The Pill became the symbol of the Sexual revolution with its origins in women's sexual liberation. It also came to be associated with population control, regardless of the possible side effects. It was regarded as a mark of scientists' triumphing over nature, and the Pill provided women with a new sense of independence whereby they exercised freedom over their bodies without the inconvenience of unwanted pregnancies. It also paved the way towards women's equality and liberty; in this regard, the Pill and the sexual revolution coexisted. The sex act was separated from reproduction. There were, however, adverse consequences such as out-of-wedlock births, sexually transmitted diseases, teen pregnancy, and divorce and adoption of unwanted children, which increased considerably. Children living in single-parent families tripled around this time. This did not go without feminist criticisms. A characteristic of this time, however, was that women were advancing dramatically and claiming their freedom and rights.

\section{The gender revolution}

Interest in gender and gender identity grew in leaps and bounds in the last 50 years, and research into genetic, hormonal, and environmental factors that affect gender identity had become an intense topic. All this ensued to obtain a better definition of what exactly constitutes gender and gender identity. It is clear that the whole landscape of gender has shifted and a brief historical presentation of the process will clarify the ramifications of terms such as man and woman, male and female, masculinity and femininity in modern society. According to West and Zimmerman (1987:137), gender is not something we are born with, and not something we have, but something we do. In the words of Butler (1990:preface), gender is something we perform, gender is learned, it is acquired.

The term gender, however, relates to a person's self-identity. It refers to (De Francisco \& Palczewski 2007):

$[H]$ ow much a person associates herself or himself with the masculine or the feminine or both as prescribed by society $[\ldots]$ [Since gender] is cultural rather than biological, the assumption is that a person can identify to varying degrees with masculinity and femininity, rather than just with one or the other. (p. 10)

Gender Identity, according to De Francisco and Palczewski (2007:10), is something a young child will know at a very young age. As soon as a child is able to talk, she or he will be able to say 'I am a boy or I am a girl'. Sociologically gender identity is mostly aligned with the biological sex and the child identifies with it. By the age of four, when a child goes to pre-school, she or he will have a stable sense of gender identity as they will behave in a stereotypical manner (such as boys go to the boys' bathrooms, girls go to the girls' bathrooms) and choose stereotypical colours, toys and clothes. However, for some children, gender identity is not so straightforward; they go through stages of ambiguity, just as a child could be born with sex ambiguity. Sex ambiguity differs from gender ambiguity: sex ambiguity refers to children being born with ambiguous external genitals or ambiguous internal organs (testes and ovaries). For some children to identify as another gender may be temporary, but for others it is permanent. It is possible that if a child is gender nonconforming, that individual can grow up transgender, meaning that the person identifies with a gender that is not in line with the sex that is assigned to him or her at birth. These children are often subjected to ridicule and bullying because they do not conform to social and cultural stereotypes.

\section{Premodern understanding of gender}

In the premodern era, was a fixed understanding there because it was solely based on biological characteristics with of gender fixed expressions and fixed roles that were reinforced by tradition, society and culture. The gender identity of human beings was defined as man and woman, and there was a firm belief that the physical identifiable characteristics were permanent and rooted in nature. So 
gender was based on the physical, namely the genital differences between man and woman, and the Bible was often used to sustain this belief that God created Adam and Eve, and he created them male and female. So God created humankind in God's own image, in the Image of God, God created them; male and female God created them (Gn 1:7).

Premodern views about gender relations were largely based on the level of assumptions rather than on informed knowledge. Attitudes about men and women were rarely scrutinised or reflected upon and the attitudes were largely formed and supported by culture and society. Gender was determined by family patterns, work roles, social policies and even the education curriculum (in this sense subjects for girls to study were prescribed as well as for boys). All this was reinforced by advertising, literature, cultural and social stereotypes and practices. Men are generally presented as tall, strong and authoritative, whereas women were put forward as passive, responsive, attractive and submissive.

The stereotypical gender attitudes of premodernity became normalised in the minds of boys and girls, and men and women in turn gave expression to them. Gender clichés were developed and were justified by social practices such as:

- A woman's place is in the home.

- The woman is intuitive, nurturing, emotional and good with her hands.

- A woman is easily distracted.

- A man is strong, objective, analytical, hardy and singleminded. He is tasked with leadership and protection.

- A man leads and a woman follows.

- Men are not emotional and women are easily influenced by feelings.

- Men were rewarded for being tough, uncompromising and defeating the opposition.

- For men to show emotions other than loyalty, pride at achievement, competition, and anger was considered to be unmanly.

Societies and cultures that abide by these attitudes were praised and awarded. Subsequently the feminists perceived this as patriarchal and these stereotypes came to be criticised with disapproval and disdain. These stereotypes were justified as being natural, biological and God-given as they were rooted in nature, in biology. The forces of biology were fixed, definitive and unchanging. These stereotypes were givens, indelible, non-negotiable for all human authority structures (Storkey 2000:13). For a man or woman to move away from all their given characteristics and move to those of the opposite sex was scandalous. Such a move was regarded as going against nature. A man was a man and a woman was a woman and there were prescribed ways for them to function as men and women. Both the Church and religious authorities tried to find biblical justification for this because nature was created by God and it was God who created man and woman, male and female (Gn 3). The blurring of sexual distinctives (unique characteristics) was regarded as transgressing the very will of God; it was against the natural order, tradition and what was divinely designed.
What was evident in this era was that there was no differentiation between sex and gender. Gender was determined by sex and biology provided the essentials thereof, and in turn it delivered the structure of all human roles and relationships. Culture and society determined the roles and behaviour of women and men. To alter the established gender roles was regarded as 'desexing humanity'. As a matter of interest, these attitudes were also used against women's ordination in the UK Anglican Church; they are still used today in the Catholic Church. Gender identity was experienced through sexuality and this was reinforced by psychologists and biologists. Christians who believed that the sex roles, the roles of men and women, were willed by God and reinforced by scripture, were very pleased that their ideas were scientifically and/or biologically supported. This argument was very powerful, but with subsequent research, fundamental flaws were revealed concerning this approach. Subsequent research pointed out that biology is definitely not the full story. Subsequent research showed that gender identity and variations are not restricted to these biological factors.

\section{Modernism and gender (1960-1970)}

Feminists were among the first to rebel against the perception that biology is the destiny of men and women's identity. Feminists were fighting for the liberation of women and the provision of the contraceptive pill, and abortion was regarded as a means towards liberation; in this sense, women believed that it provided them with the right to decide over their bodies and when and when not to have children. This was not the masculisation of women and neither the feminisation of men. This era saw the moving away from biological reductionism (the primacy of biology) towards all kinds of possibilities that were opening up. What feminism did was to focus on similarities between men and women, rather than on differences. They emphasised that they share many characteristics, capabilities, intellect, and thus reveal that women need equality and access to education and training. They clamoured for gender-segregated structures to collapse and cease to exist (Storkey 2000:25).

\section{The migration from sex to gender}

The significant progression from premodernity to modernity saw the migration from natural to socially constructed human beings. This witnessed the migration from sex to gender in this sense that human beings are as much products of social change as of biological evolution. In modernity, the shift took place from the genetic, reproductive and physiological differences of biology to the social construction of a person. This era realised that to focus on sex, male and female, is a limited way to understand the complexities of man-woman and their relationships. Because so much that occurs within relationships is not about sex, but about gender, it is essential to understand that to be feminine or masculine is related to culture, nurture, expectations and social traditions, whereas maleness and femaleness constitute other differences. 
Maleness has to do with the person's natural condition, namely the sex, physical appearance of the male, and masculinity is the cultural construct, that is the gender. To be a man and a woman implies that one has to learn to be masculine or feminine. Different cultures learn differently, how to be masculine and feminine, according to the expectations and mind-sets of the culture. The discourse, however, changed in this era, the biological differences were left behind, though not altogether, and the focus became on how culture and society construct people into femininity and masculinity. The focus was more on equality, instead of on similarities between the sexes. Unequal treatment, unequal access to power, unequal participation in decision-making were factors that concealed similarities and it was the task of feminism to challenge unequal structures and practices.

\section{Postmodernism and gender (1970-)}

Postmodernism takes the debate beyond whether our sexuality is constructed or created. The argument of modernity is on the distinction between sex (created) and gender (constructed). Postmodernity rejects the differentiation between sex and gender and argues instead that all identity is constructed and that this includes sexuality (Storkey 2000:37). Postmodernity is characterised by the fluidity of shifting images and styles. It brought along the human capacity to negotiate one's own identity without needing someone else to define who one is. There is a multiplicity of options from which to choose one's own style and one's own values. All we need to do is to live at ease within a pluralism of meanings and choices and cease to battle with outmoded world views or absolutist explanations. Postmodernity offers a far more intense critique of gender than anything that has come before. It deals with the question whether gender is created or constructed. The most important factor is that we have to decide for ourselves what it is to be a man or a woman, not to be dictated by culture and society. Our physical sexuality ceases to define a man or a woman; there is no natural way to be a man or a woman because there is such a wide variety of cultural styles of masculinity and femininity to choose from or the combination thereof. Postmodernism puts emphasis on the fact that we choose a gender identity from a multiplicity of gender identities (as indicated on page two). They query whether human sexual identity or gender identity is constructed or created; they ask what constitutes gender identity because ultimately there is no identity to be had: only a series of experiences. The writings of postmodernism have not readily been translated from academia to round-the-table conversations. Postmodernists were accused of trying to avoid differences and promoting gender neutrality. Hence the book of John Grey: Men are from Mars, Women are from Venus (1992). The aim was to be less judgmental about gender differences. The debate continues into this present era.

\section{Gender identity versus sexual identity}

From the above, it is clear that gender identity is definitely not as straightforward as it is presented to be, yet, it is important to understand that sexual identity is mostly biological and gender identity is generally socially constructed. Intersexuality refers to a person who has ambiguous sexual features, meaning the person has mixed genitalia (of females and males). This person is described as intersexed, but not necessarily transgender, but they can overlap depending on the person's choices. According to Sally Gross (Coan, The Natal Witness, February, 2000), who was an intersexed person:

[T] here is no neat definition of this state; one attempt defines it as 'atypical congenital physical sexual differentiation'. However, intersex, she says: 'is really an umbrella term, which covers an enormous range of physical sexual permutations'. Those people born very obviously intersexed are thought to be one in 2000 . Gross is quick to point out[explains] that there is a distinction to be made between biological sex - one's anatomy - and sexual orientation. Some intersexed people are attracted to men, others to women; some do not have any sexual orientation at all and are thus asexual. 'Sexual orientation is not an intrinsic part of the intersex package', says Gross. 'When it comes to intersexuality, one's bodiliness is such that it's often exceedingly difficult to answer the question: is this person male or is this person female?' [...] Gross points out that the way biological sex develops is complex, and cannot always be regimented into a straightforward classification of a person as either male or female. At least five variables come into play: external genitals, chromosomal patterns, dominant sex hormones, the nature of the person's sex glands and the internal structures of reproduction - these jointly result in the person's physical sexual type. 'But none of these are absolutes', says Gross. She says: 'You get in-betweens, even within the single variables. All sorts of permutations occur. What is needed to yield unambiguous male or female is for all five of these variables to be completely congruent with one another and unambiguous in themselves? Nature and the mathematics of it all ensure that many other types of outcomes are in fact possible'. (pp. 21-23)

When a person is 'non-congruent or transgender [it] means that the person feels that her or his biological sex and genitalia do not match her or his gender identity' (De Francisco \& Palczewsk 2007:13). This implies that a person could physically possess male genitalia, but does not feel male and vice versa. The concepts gender identity and transgender differ in turn from a person's sexual orientation. Sexual orientation is perceived as a person's sexual, romantic attraction to another person, male or female; and gender identity is a person's innate sense of being a man or woman. Transgender is then a person who is physically male who feels that he is really in a female body, and vice versa. Therefore, the male has a female gender identity and the female has a male gender identity (transgender). Therefore, a male would say that he is a female trapped in a male body, or a female would say that she is trapped in a male body.

Sexual identity: it is the label people adopt to signify to others who they are as a sexual being, particularly regarding sexual orientation. Generally, people adopt a sexual identity that matches their sexual orientation - for example, a heterosexual person is heterosexually oriented, and a homosexual person identifies as lesbian or gay. There is, however, a large group of people for whom sexual orientation does not match their sexual identity. 
Sexual identity has moved away from the two sexes (male and female) and two genders (women and men) in the growing visibility of intersexed and transgender persons. Sexual identity has moved to incorporate persons who identify themselves as bisexual (two) and others who identify as pansexual (meaning multiple). Sexual identity becomes more intricate with the fluidity and diversity of gender and sexual orientation. Then there are also those people who identify as asexual, for example they do not experience sexual attraction to any gender.

Although a child may know from a very early age what his or her gender is, that is not the case with sexual orientation. Sexual orientation comes much later and often has nothing to do with gender identification. As stated by De Francisco and Palcsewski (2007):

Sexual orientation is therefore not the same as gender or sex. Sexual orientation refers to whether one [a person] is physically and romantically attracted to or has sex with persons of the same sex, the other sex, or both (as in the case of bisexuals). Sexuality is more than orientation: it involves what one [a person] does when one $[s / h e]$ is sexual. [... The identity of] a gay, lesbian, heterosexual, bisexual, or transgendered person is also confounded [often confused] with the terms gender and sex. Part of the confusion is due to [caused by] social stereotypes [in this sense that] gays are assumed to be effeminate, and lesbians are assumed to be masculine. (p. 10, [author's own italics])

This is often not the case, a very strong male rugby player can be homosexual: thus sexually attracted to someone of his own sex. A queer is a person that does not abide by heteronormative sex practices and even a heterosexual person can be labelled queer. Transgender and non-binary people often describe themselves as queer when it comes to their sexual attraction and practices. A person that is asexual generally describes him or herself as having no sexual feelings or orientation either way.

A person that claims to be bigender or dual gender embraces both genders depending on the context or situation. The bigender person can be feminine, masculine, agender or androgynous, or practice two genders simultaneously.

A transsexual man or woman is described as a subset of transgender persons, and they wish to transition to the gender with which they identify and search reassignment surgery. Transsexuality is based more on the physical aspects, whereas transgender deals with a person's psychological gender disposition and the social and cultural expectations that accompany the gender role. Transsexuality has to do with a person's physical sexuality and is not gender related. The sexual orientation of transsexual men and women may be heterosexual, homosexual or bisexual. It is understood that heterosexual female-to-male transsexuals are sexually attracted to women, and heterosexual male-to-female transsexuals are sexually attracted to men (Golombok \& Fivush 1994:4). Often to deal with this transsexual state, the person will cross dress or some who can afford it will go for a sex-reassignment operation and obtain the physical characteristics of the sex they wish to be.
It is, however, important to realise that to know a person's sexual orientation does not tell us about the person's gender and their gender role. Lesbian women may reveal traditionally feminine or masculine gender roles just as heterosexual women and men may also show traditional feminine and masculine gender roles. A lesbian woman knows that she is female and a gay man knows that he is male, so too does the gender identity of most bisexual men and women match their biological sex. Their sexual attraction is to their own sex.

The above explanations of sexual and gender variations are only the tip of the iceberg, but the question is: Is theology and society abreast with the gender and sexual revolutions of the day?

\section{A non-gendered idea of humanity in theology and philosophy}

Although the idea of gender as transcending bodily sex is a recent one, in theology and philosophy, it remains a very old debate. It has its roots in traditional philosophy with its aspirations connected to the transcendence or consciousness over the physicality of human nature: transcendence over animality, that is, the physical needs of human beings, as opposed to the spiritual needs, of the autonomous will over the passivities of nature. The biblical and theological presentations on sex and gender is time- and era-based and limited to the available knowledge of the times. Their discourse pertaining to sexuality and gender comes from the tradition that God is the creator of man and woman, as testified in Genesis 1.28. According to Augustine, being created in the Image of God - male and female - was seen as first created as a spiritual unity without the division of male and female. This Image, explains Radford Reuther Rosemary (2007:52), who interprets Augustine, refers not to the physical body, but to the 'interior man' or intellect, that rules over the lower creation and contemplate eternal things. According to the philosophical reasoning of Augustine, male and female originally meant the union of mind and soul, sapientia and scientia, the mind or wisdom being masculine and the soul, which mediates sense knowledge, feminine. In their original harmonious union, the male part would have ruled over the female part of the inner self. Together, this unitary human being would have reproduced mentally, creating 'spiritual offspring of intelligible and immortal joys' (Radford Reuther Rosemary 2007:52). Only after the Fall (the so-called Original Sin) did sexual differentiation appear. Adam and Eve created the beginning of very physical and sexually differentiated bodies - thus the gender differentiation. Up until this moment, the Non-gendered Idea of Humanity - the intellectual Image of God-was found in all humans, male and female. For Augustine, gender hierarchy was part of the original design of creation, though this is contested by feminist theologians.

The study of animalism versus humanism has an Aristotelian heritage and it is related to the ancient debate over personal identity, i.e. the search for human identity: who and what are we? According to Aristotle's philosophy, animalism 
concerns our basic metaphysical nature. The question is: Are we simple or composite, process, event or are we material or immaterial, organic or inorganic? How do we justify an immaterial soul or ego, according to Descartes, or the material body, asked by Thompson (1989:1-47). What about body and soul complexes? Once we can answer the question: who are we, we may be able to place gender into its rightful context as well as gender mutuality? As seen above, in the traditional philosophical debate, the concept of male and female is not important; it is the rational mind that is essential and it is perceived as neither sexed nor gendered. The idea of a (Lloyd 1989):

[S]exless soul, which reinforces the idea of gender as changeable goes back to Plato's discussion of the female guardians in Book Five of The Republic. [... Hence] the sexual equality of the guardians rests on their sameness of the soul, which co-exists with bodily difference. (pp. 1-47)

Theologically speaking, sexuality is part of God's creation and the differences between man and woman are biblical assumptions that are ordained by God and form part of the structure of human identity. The fathers of the early church sustained this, and women were largely blamed for the evil of the world. Ancient theologians described women as the devil's gateway, misbegotten men, and women's differences from men as well as their sexuality were regarded as very problematic. Women's sexuality was regarded as a temptation for men, which drew them away from their purity. St Jerome even intimated that God found displeasure in women, and because of their uncleanliness they should live a life of squalour and dirt so that they do not attract men. These were the worst excesses of a premodern mentality that belonged to history and not to contemporary Christianity. Sadly, these attitudes remained within the church and among churchmen and among some even up until today (Storkey 2000:86). Often theologians tried to find biblical and cultural substantiation for these perceptions. The whole female-male discourse is permeated by their biological differences and it is these physical or biological differences that bar women from the priesthood. Priests, particularly in the Catholic and Orthodox churches, are regarded as representatives of Jesus Christ because Jesus was male, physically male. Because women have the 'wrong kind' of genitals and, hence, they possess the wrong physical form it was concluded that they cannot be a representative of Jesus Christ, and therefore cannot perform priestly acts. It is important to realise that the creation story stated in Genesis is more than just the biological assignment of Eve as child-bearer and Adam as breadwinner. God created the human race, and God created both man and woman in God's Image. 'God created them, and God blessed them, and said to them, to be fruitful and multiply' (Gn 1:28). Together, as man and woman, they are in the Image of God, not separately. This is inclusive (man and woman) and the allocation of different tasks to men and women was a cultural attribute and not biblical. Biblical feminism rejects the biological reductionism and reaffirms that culture is the key that shapes gender roles. Biblical feminism rejects the retelling of scripture to support patriarchy, male authority and women's subordination and exclusion. Elizabeth Fiorenza (1985) stated that:

[T] he bible is used against women in our liberation struggle, and perpetuates alienation from ourselves and at the same time provides authorisation and visions for Christian women in our struggle against patriarchal racism, sexism, classism and colonialism. (p. 75)

Gender that is based on biblical and early theological interpretations is confined to male and female, man and woman, and feminine and masculine connotations.

On the evolution of gender, we see that Freud viewed gender as fundamental in the construction of the subject. Feminist theorists distinguish between our biological sex and our cultural gender. Sex refers to our anatomy and the biological substance; gender is seen as the social construction of what male and female mean in a given socio-historical context. The understanding of gender has moved beyond the culturally and linguistically created and recreated understanding thereof. Gender identity has taken on a meaning that is fluid, multiple and relative. Sexual differences do not signify subjective gender differences. In the evolution of the concept gender, it is possible that the time has come to transcend the concept gender by adopting a non-material self-consciousness. In the philosophy of transcendence, the word transcend conveys the literal Latin meaning, which means climbing or going beyond. The ontology of the human person's (studying the nature of being, becoming what one is meant to be) gender is of no consequence or of consequence? Similar to Nietzsche, who did not, per se, deny or acknowledge the existence of God with his statement: 'Gott ist todt!' His was a reaction to the concept of God held in his time, namely the modernistic period's belief in a concept of God tied to the progress in history, rationality and morality. To Nietzsche the God of his time was dead (atheism). He spelt out an important consequence of this death, namely nihilism (nothingness). A similar approach can be rendered here that the concept 'gender' the way we understood it traditionally is dead. God has no gender: The Catechism of the Catholic Church (CCC) teaches that God transcends the human distinction between the sexes, hence God is God. Gender has become a human linguistic constraint for both human and divine (John Paul 11 1992:239). This we have to overcome or transcend.

\section{Love is androgynous by nature}

Do we need a specific gender to love? Do we need a sexual or gender identity to love? If love is confined to gender, then the whole concept of love is dishonoured. Sexual attraction needs to be disconnected from love, just as love needs to be detached from gender. Love is an entity on its own and does not need a sex or a gender to provide it with meaning. Love is androgynous by nature; it is genderless because a human person has the capacity to love regardless of the gender and sexuality. The genital property is only one dimension of the sexual reality of the human species. Much more is needed to experience and negotiate love, intimacy, tenderness and mutuality. These are features of human life that none of us can 
do without: deprived of these qualities, we stand little chance of realising our full potential as incarnational human beings. Human love relations are important and require deeper levels of mutuality and reciprocity.

\section{The state of being mutual and the mutuality of love}

Mutuality of being, or mutuality of persons, refers to a relationship between people who are 'intrinsic to one another's existence, to life itself, pertaining to "intersubjective belonging"' (Sahlins 2011:2). In social philosophy, intersubjective belonging refers to the components of human togetherness and 'to live a human life is to experience oneself as belonging to different communities within which human individuals encounter and converse with one another' (Peperzak 2000:5). The moral obligations of intersubjectivity (Hegel's [1977] terminology) coincide with the demands of our belonging to a family, to social communities and a state. This implies face-toface relationships, people encountering each other directly and not being observers. The mutuality is based on liberty, equality, universal human rights and individual freedom inherent to the human person. What is stable and enduring is the communally recognised mutuality of being between parties involved, instead of the feelings between the parties in the relationship. This mutuality of being can be based on biological ties, but can also be equally based on socially constructed ties. As a result, it helps affiliation to transcend the dualism of nature and culture that has long haunted this field. Mutuality of being exists therefore in the realm of human consciousness. The general understanding of mutual or mutualism is the manner in which two organisms of different species exist in a relationship whereby each benefits from the presence of the other.

Mystics speak of God as being Love: the Being and Love is coterminous and is therefore equal in scope. God is love (1 Jn 4:8). Anyone who does not love does not know God, because God is love (1 Jn 4:16). True love with its root in Sanskrit lubh means desire, but it is desired for the well-being of the other. Love contains altruism (alterity - from the Latin). Altruism means the care of others for the sake of the other. Alterity means otherness, feeling for the other, being aware of the ineffable otherness of the other, but the other is a subject in their own right, in all its glorious alterity. Loving the other is not gender bound, but breaking through the veil of obscurity, valuing the other in the truest unfathomable capacity and irreplaceable particularity. Love is thus real-making, feeling understood and accepted in all its complexity, by someone, who provides a sense of meaning and human flourishing. Love designates the existence of someone on whom one becomes imprinted, to whom one becomes attached, bonded, one who justifies one's acceptance of the stark fact of incompleteness. No longer can one function as an autonomous androgyne, because love is mutual.

Does homophilia make gender love, mutual? The theory of homophily states that 'similarity breeds connection'. Studies of homophily have linked attraction between individuals based on similarly shared demographics. These may include, but are not limited to, race, ethnicity, gender, and socioeconomic status. Heterophilia (as the opposite of homophilia) or love of the different is the tendency of individuals to collect in diverse groups; it is the opposite of homophily. The state of being mutual can be expressed by a feeling or an action by a partnership of any kind and this is done with reciprocal respect and understanding. The mutuality is marked by commonalities, rather than by differences; it is based on that which is correlative, such as human rights.

\section{Mutual love and sexuality}

Most people have a spurious understanding of human sexuality and Diarmuid O'Murchu (1999:41) suggests that a spurious understanding is fundamentally violent to both the Divine and Human, to both God and people. He says sexuality is portrayed as belonging to the unruly passions and instincts, whereas it ought to be about joy and pleasure, but often it is the opposite, pain and destruction. Sexual ecstasy is at the core of divine creativity. Human beings are sexual beings regardless of the gender of the person and the sexuality. It is sexuality that activates the capacity to relate whereby we come to know the self and the other and the interactive mutuality that is central to the experience of being human. More than any other aspect of our selfhood, says O'Murchu (1999:49), our sexuality establishes our human uniqueness. Our sexuality is a form of psychic energy, always seeking expression. If we do not channel this energy in creative ways, innocent and vulnerable people often become the victims of our sexual projections.

O'Murchu (1999:49) suggests that sexuality and love ought to be expressed in their liminal context. In traditional biblical terms, the liminar is in this world, but not of it. The liminar is a full sexual person, with all the feelings, emotions, desires and possibilities of that deeply creative urge, but the call to liminal space requires a different way of living out our sexual relatedness. Our sexuality is at the very best of what it means to be human, innate to the imago dei in which we are all created. Love is mutual when love is love only as freedom. Freedom is an ethical principle: freedom is freedom only as love, and love is love only as freedom. To encounter another in love does not limit freedom. Instead, it is the unfolding and fulfilment of freedom.

The love command in scripture is the love of God and love of neighbour (Rosner 1994:21). The love command was central to Jesus and is usually equated with the ethics of the Gospel. Jesus ethically guided the behaviour of his followers by giving a new commandment: 'Love one another'. This, in fact, is the only moral rule given by Jesus in John (13:34-35). Van der Watt (2006:1160), in reflecting on the saying of Jesus in John's Gospel, namely: 'that you love one another as I have loved you ...' perceives it as an expression of egalitarianism and hence mutuality. He claims that it implies common reciprocation within a particular group and it implies social interdependence (Van der Watt 2006:1160). If love was central to the message of Jesus, the 'Jesus quality' of this love qualifies the correct practicing of freedom. The commandment to love is radicalised as expressed in Galatians 5:14; this law to love is 'redefined and 
radicalized in Jesus as unconditional, universal, self-sacrificing love, and exemplified by Jesus in his life and death' (Du Toit 2006:175). Love concentrates primarily on the positive inner disposition of the believer towards God and neighbour, which results in a specific style of living and doing. For this reason, it is understandable that love deals with the innermost being of a person, which emanates into their outward behaviour and without love outward actions are meaningless (Du Toit 2006:176). Love is the first on the list of the fruits produced by the Spirit ... 'for the fruit of the Spirit is love, joy peace ...' (Gl 5:22). Love is genderless; true love is degendered and free.

\section{Conclusion}

Theologically speaking, all division (including gender division) is the result of 'Original Sin', and love heals all divisions. The skill of efficacious love is the ability to allow each person to remain a separate individual vis-a-vis the other, and at the same time being able to remain immersed in an indivisible duality. Love establishes mutuality and transcends gender differences. Love does not require a gender, but withdraws into the other's 'inner world' where gender is non-existent. Love is the ground of mutuality and provides recognition to the existence of the other. The Idea of a non-gendered humanity is to embrace the spiritual capacity to transcend all gender boundaries, gender roles, gender expectations and stereotypes. Love embraces all and facilitates mutuality.

\section{Acknowledgement Competing interest}

The author declares that no competing interest exists.

\section{Author contributions}

I declare that I am the sole author of this research article.

\section{Ethical consideration}

This article followed all ethical standards for carrying out research without direct contact with human or animal subjects.

\section{Funding}

This research received no specific grant from any funding agency in the public, commercial, or not-for-profit sectors.

\section{Data availability statement}

Data sharing is not applicable to this article as no new data were created or analysed in this study.

\section{Disclaimer}

The views and opinions expressed in this article are those of the authors and do not necessarily reflect the official policy or position of any affiliated agency of the authors.

\section{References}

Baker, J.H., 2012, 'Margaret Sanger: A life of passion', Hill \& Wang, New York.

Boylan, J.F., 2011, 'The XY Games' New York Times 8/03/08 in metaphysics of gender, Charlotte Witt, Oxford University Press, Oxford.

Butler, J., 1990, Gender trouble: Feminism and the subversion of identity, Routledge, New York.

De Francisco, V.P. \& Palczewski, C.H., 2007, Communicating gender diversity: A critical approach., Sage, Thousand Oaks, CA.

Du Toit, A.B., 2006, 'Shaping a Christian lifestyle in the Roman capital', in J.G. Van der Watt (ed.), Identity, ethics, and ethos in the New Testament, pp. 167-198, assisted by Francois S. Malan. Walter de Gruyter, Berlin.

Eckert, P., 1996, Vowels and nail polish: The emergence of linguistic style in the preadolescent heterosexual marketplace. Gender and belief systems, ed. Jocelyn Ahlers et al., Berkeley Women and Language Group, Berkeley, CA.

Eckert, P. \& McConnell Ginet, S., 1996, Language and gender, 2nd edn., Cambridge University Press, Cambridge.

Edwards, A., 2010, 'The sex gender distinction. Has it outlived its usefulness?', Australian Feminist Studies 4(10), 1-47. https://doi.org/10.1080/08164649.1989. 9961648

Fiorenza, E., 1985, 'Roundtable discussion: On feminist methodology', Journal of Feminist Studies and Religion 1(2), 75.

Golombok, S. \& Fivush, R., 1994, Gender development, Cambridge University Press, Cambridge.

Grey, J., 1992, Men are from Mars, women are from Venus: A practical guide for improving communication and getting what you want in your relationships, Harper and Collins, London.

Hegel, G.W.F., 1977, Phenomenology of spirit, Oxford University Press, Oxford.

Lloyd, G., 1989, 'Woman as other sex, gender and subjectivity', Australian Feminist Studies 4(10), 1-47. https://doi.org/10.1080/08164649.1989.9961649

National Geographic, 2017, 'Gender revolution: The shifting landscape of gender', National Geographic 231(1), 2-73.

O'Murchu, D., 1999, Poverty, celibacy and obedience: A radical option for life, Crossroads Publishing Company, New York.

Peperzak, A.T., 2000, 'Intersubjectivity and community', in Phenomenology of the political, pp. 55-64, Loyola University of Chicago, USA, Chapter. Part of the Contributions to Phenomenology book series (CTPH, vol. 38), Chicago, IL: Loyola University Press.

Radford Reuther Rosemary, 2007, Sexuality, gender and women in feminist interpretations of Augustine edited by Judith Chelius Stark, The Pennsylvania State University Press, University Park, PA

Rosner, B.S.P., 1994, Scripture and ethics: A study of 1 Cor. 5:7, E.J. Brill, Leiden. https://doi.org/10.1163/9789004332751_004

Sahlins, M., 2011, What kinship is (part one), Department of Anthropology, University of Chicago, Chicago, IL. Journal of the Royal Anthropology Institute. https://doi. org/10.1111/j.1467-9655.2010.01666.x

Stoller, R., 2010, 'Sex and gender: 40 years on', Archives of Sexual Behavior 39(6), 1457-65.

Storkey, E., 2000, Created or constructed?: The great gender debate, Paternoster Press, Carlisle.

Thompson, D., 1989, 'Women as other: Sex, gender and subjectivity', Australian Feminist Studies 4(10), 1-47. https://doi.org/10.1080/08164649.1989.9961648

Thompson, K. \& Embree, L., 2000, Phenomenology of the political, Published Florida Atlantic, University Boca Raton/Kluwer Academic Publishers, Dordrecht.

Van Der Watt, J., 2006, Identity, ethics and ethos in the New Testament, ed. J. Van der Watt, assisted by F.S. Malan. Walter de Gruyter, Berlin.

West, C. \& Zimmerman, D.H., 1987, 'Doing gender', Gender and Society 1(2), 125-151. https://doi.org/10.1177/0891243287001002002 